\title{
Cognitive reserve as a moderator of the negative association between mood and cognition: evidence from a population-representative cohort
}

\author{
Carol Opdebeeck ${ }^{1}$, Fiona E. Matthews ${ }^{2, .3}$, Yu-Tzu Wu ${ }^{4,5}$, Robert T. \\ Woods $^{6}$, Carol Brayne ${ }^{7}$, and Linda Clare ${ }^{4,5,8}$, on behalf of the Cognitive \\ Function and Ageing Study Collaboration* \\ ${ }^{1}$ Division of Neuroscience \& Experimental Psychology, School of Biological \\ Sciences, The University of Manchester, UK. ${ }^{2}$ Institute for Health and Society, \\ Newcastle University, UK. ${ }^{3} \mathrm{MRC}$ Biostatistics Unit, Cambridge, UK ${ }^{4} \mathrm{REACH}$ : The \\ Centre for Research in Ageing and Cognitive Health, School of Psychology, \\ University of Exeter, UK. ${ }^{5}$ PenCLAHRC, University of Exeter Medical School, UK. \\ ${ }^{6}$ DSDC Wales, Bangor University, UK. ${ }^{7}$ Department of Public Health and Primary \\ Care, Cambridge Institute of Public Health, School of Clinical Medicine, University \\ of Cambridge, UK. ${ }^{8}$ Centre for Research Excellence in Promoting Cognitive Health, \\ Australian National University, Canberra, Australia. \\ * See CFAS collaborators at end of the paper
}

Correspondence to: Dr Carol Opdebeeck, Division of Neuroscience and Experimental Psychology, The University of Manchester, Zochonis, Brunswick Street, Manchester, M13 9PL, UK.

CFAS II has been supported by the UK Medical Research Council (research grant: G06010220) and received additional support from the National Institute for Health Research (NIHR), comprehensive clinical research networks in West Anglia, Nottingham City and Nottinghamshire County NHS Primary Care trusts and the dementias and neurodegenerative disease research Network (DeNDRoN) in Newcastle. This research was done within the UK National Institute of Health Research collaboration for leadership in applied health research and care for Cambridgeshire and Peterborough (CLAHRC EoE), and the Biomedical Research Centre infrastructures at Cambridge and Newcastle upon Tyne. FEM is supported by the MRC (research grant: U105292687).

Word count: 3,523 


\begin{abstract}
Background: Cognitive reserve (CR) has been associated with better cognitive function and lower risk of depression in older people, yet it remains unclear whether CR moderates the association between mood and cognition. This study aimed to investigate whether a comprehensive indicator of CR, including education, occupation, and engagement in cognitive and social activities, acts as a moderator of this association.
\end{abstract}

Methods: This was a cross-sectional study utilising baseline data from the Cognitive Function and Ageing Study II (CFAS II), a large population-based cohort of people aged 65+ in England. Complete data on the measures of CR, mood, and cognition were available for 6565 dementia-free individuals. Linear regression models were used to investigate the potential modifying effect of CR on the association between cognition and mood with adjustment for age, sex and missing data.

Results: Levels of CR did moderate the negative association between mood and cognition; the difference in cognition between those with and without a clinical level mood disorder was significantly smaller in the middle $(-2.28 ; 95 \% \mathrm{CI}:-3.65,-0.90)$ and higher $(-1.30 ; 95 \% \mathrm{CI}:-2.46,-0.15) \mathrm{CR}$ groups compared to the lower CR group $(-4.01 ; 95 \%$ CI: $-5.53,-2.49)$. The individual components of CR did not significantly moderate the negative association between mood and cognition.

Conclusion: These results demonstrate that $\mathrm{CR}$, indexed by a composite score based on multiple indicators, can moderate the negative association between lowered mood and cognition, emphasising the importance of continuing to build CR across the lifespan in order to maintain cognitive health. 


\section{Introduction}

Dementia and cognitive decline have been associated with increased disability and mortality and account for a significant proportion of care expenditure for older people (Comas-Herrera et al., 2011; Di Carlo et al., 2000; Langa et al., 2008; Pérès et al., 2005; St John et al., 2015; Tinetti et al., 2011). In the UK, an earlier analysis has suggested that the continued growth of the ageing population will potentially result in 3.7 million people with cognitive impairment by 2026 , which if realised would result in greater healthcare costs (Jagger et al., 2009). Given the individual, family, and societal burden of dementia and cognitive decline, it is important to identify potential risk factors and develop effective strategies for prevention or risk reduction. Indeed, estimates suggest $28.2 \%$ of the population-attributable risk of developing Alzheimer's disease could be related to potentially modifiable factors (Norton et al., 2014).

Depression and anxiety are common mood disorders which affect approximately $10 \%$ of people aged 65 or above in Western Europe (McDougall et al., 2007; Copeland et al., 2004). These common mood disorders, especially current experience of depression, have been associated with poorer cognitive performance and an increased risk of cognitive decline, mild cognitive impairment (MCI), and dementia (Diniz et al., 2013; Reppermund et al., 2011; Steffens et al., 2014; Yates et al., 2013). A recent meta-analysis has suggested that approximately $10 \%$ of dementia cases could be prevented if depression is addressed (Norton et al., 2014). In addition, a comprehensive review of existing evidence combined with consensus by eight experts indicated that there is good evidence that depression is a modifiable risk factor for cognitive decline and dementia (Deckers et al., 2015).

The associations between lowered mood and cognitive decline or dementia may be due to a shared underlying mechanism (Byers \& Yaffe, 2011; Korczyn \& Halperin, 
2009; Leonard, 2007). Depression in later life and poorer cognitive performance are both associated with white matter hyperintensities, hippocampal atrophy, and decreases in total brain volume (Ballmaier et al., 2004; Debette \& Markus, 2010; Elbejjani et al., 2015; Enzinger et al., 2005; Lampe et al., 2003; Nebes et al., 2001; O'Brien et al., 2004). These pathological overlaps suggest that perhaps factors that are protective against cognitive impairment and decline may also be protective against depression in older people and could be of benefit in moderating the association between mood and cognition.

One such factor could be cognitive reserve. Cognitive reserve is built through engagement in cognitively engaging activities across the lifespan, including educational level, complex occupations and cognitively-stimulating leisure activities (Richards \& Deary, 2005; Richards \& Sacker, 2003; Whalley et al., 2006; Stern 2002; 2009 ; 2011). Several reviews indicate that greater cognitive reserve is associated with better cognitive performance in healthy older people and a reduced risk of cognitive decline and dementia (Fratiglioni \& Wang, 2007; Harrison et al., 2015; Meng \& D’Arcy, 2012; Opdebeeck et al., 2016a; Valenzuela \& Sachdev, 2006a; 2006b). Higher levels of cognitive reserve have also been associated with reduced levels of depressive symptoms (Lorant et al., 2003; Opdebeeck et al., 2016b; Paulson et al., 2014).

At present, research into whether cognitive reserve moderates the association between mood and cognitive function has produced conflicting results. A review of studies assessing whether cognitive reserve moderates the association between mood and cognition concluded that there was a potential modifying effect of cognitive reserve on the negative association between mood and cognitive function and decline but the result was tentative (Opdebeeck et al., 2015a). The results of the individual 
studies included in this review were varied, ranging from a moderating effect of higher education on the negative association between clinical depression and cognitive function (Pálsson et al., 1999; Pálsson et al., 2001) to reports that cognitive performance decreases as depressive symptoms increase in those with higher but not lower levels of education (Geerlings et al., 2000; O'Shea et al., 2014; Santos et al., 2014).

To address the uncertainty in the literature, the aim of this study is to investigate the potential modifying effect of cognitive reserve, measured using a composite indicator, on the association between cognitive function and mood disorders in a contemporary large population-based cohort of older people in England.

\section{Method}

\section{Participants}

Participants were drawn from the first wave of the Cognitive Function and Ageing Study II (CFAS II, version 3; http://www.cfas.ac.uk/). A total of 7,762 people over 65 completed the study between 2008 and 2011 in three geographical areas of England Cambridgeshire, Newcastle, and Nottingham - which included both rural and urban populations. More detailed information on CFAS II has been reported previously (Gao et al., 2015; Matthews et al., 2013). To avoid the potential confounding effect of dementia at prevalence and to standardise participant living situation, this study excluded those with a diagnosis of dementia or an organicity score of 3 or higher based on AGECAT diagnostic algorithms $(n=487)$ and an additional 81 people living in institutional settings. This resulted in a sample of 7,194 community-dwelling older people without dementia. 


\section{Measures}

\section{Cognitive reserve}

A composite measure of cognitive reserve, the cognitive lifestyle score (CLS), was calculated based on participants' educational level, primary occupation, and engagement in social and cognitive activities in later life. The calculation of this score was based on the CLS created in MRC CFAS, the first cohort of the CFAS studies (Valenzuela et al., 2011) with the addition of responses to questions about cognitive activities, which included the frequency with which participants listen to the radio, read newspapers, magazines, or books, play games such as cards or chess, and do puzzles and/or crosswords. These questions were added in CFAS II, making it possible to investigate current cognitive lifestyle in more detail.

Educational level was expressed as years of education completed. Occupation was assessed in line with the procedure of Valenzuela and colleagues (2011) in that the participants' main occupation was coded in terms of social class grouping (from I to $\mathrm{V}$ ) and socioeconomic grouping (11 to 150$)$, with lower scores indicating more complex occupations in each case. These two groupings were then exploded and ranked to create an occupational complexity score with a possible range of 1-14, that was more fine-grained than either grouping alone. For example, if a person had a social class grouping of I and a socioeconomic grouping of 11 they were given an occupation score of 1 . In another example, a participant with a social class grouping of IIIN (skilled non-manual) or IIIM (skilled manual) and a socioeconomic grouping between 70 and 80 would be given an occupation score of 9 in this system. Further details regarding the combinations used to create each occupation score can be obtained from the corresponding author. An additional ranking of 15 was given to housewives as these individuals do not receive a formal code in the UK social class 
ranking system. The ratings were then reversed to be in the same direction as education and social and cognitive engagement, with lower scores indicating a less active cognitive lifestyle. The later life activity score comprised the three indicators of current social engagement as utilised in the CLS created in MRC CFAS (Valenzuela et al., 2011) and the seven measures of current participation in cognitive activities added in CFAS II. Current participation in each of the cognitive activities was coded on a 5-point scale from undertaking the activity once a year or less to undertaking the activity every day. Scores for the 10 items were summed to create an overall activity score.

To enable each of the three sub-scores to contribute equally to determining whether a person's cognitive lifestyle reflected low, medium or high levels of activity, the scores were weighted to provide equal distribution across the sub-components. To determine the weights of each component the range of scores between the $25^{\text {th }}$ and $75^{\text {th }}$ percentile were examined, and the weights were calculated to ensure that all three components had equal interquartile ranges, allowing each to contribute equally to the total CLS. The total CLS was then calculated using the following formula:

$\mathrm{CLS}=(3.4 \mathrm{x}$ education $)+(2.4 \mathrm{x}$ occupational complexity $)+(1 \mathrm{x}$ social and cognitive engagement).

The CLS was slightly skewed (Skewness $=0.70 ;$ Kurtosis $=3.72)$ suggesting that it was not normally distributed. Hence the CLS was divided at the tertile level to allow for comparisons between those with lower, medium, and higher cognitive lifestyle scores, which can be considered a proxy measure for their levels of cognitive reserve. 


\section{Mood disorders}

Depression and anxiety were assessed using the Geriatric Mental State Automated Geriatric Examination Assisted Taxonomy (GMS AGECAT). The GMS is a semi-structured interview designed to assess organic and psychiatric disorders in older people. The AGECAT programme uses an algorithm to assign diagnoses to provide consistency across time and location. The AGECAT assigns scores for depression $(0-5)$ and anxiety $(0-5)$ based on clusters of symptoms. These scores were coded into groups of those with no mood disorder (GMS AGECAT for anxiety and depression $=0$ ), a sub-threshold mood disorder (GMS AGECAT for anxiety or depression $=1-2$ ), or a clinically relevant mood disorder (GMS AGECAT for anxiety or depression $=3+$ ). Absence or presence of a subthreshold or clinical level mood disorder, rather than of depression or anxiety individually, was chosen due to the strong association between depression and anxiety. Additionally, the GMS AGECAT uses a hierarchical system to determine a main diagnosis, which may give precedence to a diagnosis of depression over a diagnosis of anxiety when overlapping symptoms are reported. The GMS AGECAT has demonstrated good concordance with diagnoses by trained psychiatrists (Cohen's Kappa $=0.84$, Copeland et al., 1986) and eliminates the variability that has been observed with clinical diagnosis (Copeland et al., 2002).

\section{Cognition}

Cognition was assessed using the Cambridge Cognitive Assessment (CAMCOG). The CAMCOG provides an overall score for cognitive function from eight subscales - orientation, language, memory, attention, praxis, calculation, abstract thinking, and perception. Total scores range from 0 to 107, however as in MRC CFAS, total scores on the CAMCOG in this study could range from 0 to 103 (Williams et al., 2003). The CAMCOG has good inter-rater reliability $(r=.97)$ with 
$92 \%$ sensitivity and $96 \%$ specificity in detecting cognitive impairment, and avoids the ceiling effects seen in other brief neuropsychological assessments (Roth et al., 1986). Data analysis

T-tests and Chi Square tests were used to compare age, sex and mood disorder in those with and without missing CAMCOG and CLS information. Inverse probability weighting was then used to adjust for non-response in CFAS II (Matthews et al., 2013) as well as missing data, with weights calculated by age, sex, depression and anxiety levels.

Weighted linear regression modelling was used to investigate the association between cognitive function, cognitive reserve and mood disorder adjusting for age, and sex. To examine the potential modifying effect of cognitive reserve on the association between cognition and mood, interactions between cognitive reserve measures (the overall CLS, and the individual components of education, occupation and social/cognitive activity) and mood disorder were included in the regression models. All the analyses were carried out using Stata version 13.

\section{Results}

The 7194 community dwelling individuals without dementia included 3115 men and 3450 women, but 629 people had missing CLS or CAMCOG scores. Individuals with missing data were significantly more likely to be older, female, and to have a mood disorder (Table 1). Among the 6565 people with complete data, the mean CAMCOG score was $89.4(\mathrm{SD}=7.7)$ with a range between 42 and 103, and the mean CLS was 86.9 $(\mathrm{SD}=16.2)$. The CLS ranged from 26.8 to 156.4 with a median score of 84.6. 
**Table 1 about here**

Mood disorder was associated with poorer cognitive performance (Table 2). Compared to those without mood disorder, lower CAMCOG scores were found in people with subthreshold (-1.02; 95\% CI: $-1.44,-0.60)$ and clinical $(-3.67 ; 95 \%$ CI: $-4.59,-2.75)$ levels of mood disorder after adjusting for age, sex and missing data. A higher level of cognitive reserve was associated with better cognitive performance. Compared to those with low cognitive reserve, people with medium levels of cognitive reserve had CAMCOG scores 4.00 points (95\% CI: $3.52,4.48)$ higher and this difference increased to $6.94(95 \% \mathrm{CI}: 6.48,7.39)$ for those with high cognitive reserve when adjusted for age, sex and missing data. The relationships between cognitive function, cognitive reserve and mood disorder remained significant in the full model including all variables, although the effect sizes slightly reduced (Model 4, Table 2).

**Table 2 about here**

To investigate whether cognitive reserve modifies the association between cognitive function and mood disorder, Table 3 shows differences in CAMCOG scores by cognitive reserve and mood disorder levels. In the lower CLS group, those with subthreshold (-1.12; 95\% CI: -1.91, -0.31) and clinical (-4.01; 95\% CI: -5.54, -2.49) mood disorder had significantly lower cognitive function scores compared to those without mood disorder. However, the strength of the negative association in those with clinical mood disorder compared to those without mood disorder was weaker in the middle $(-2.28 ; 95 \%$ CI: $-3.65,-0.90)$ and higher CLS groups $(-1.30 ; 95 \% \mathrm{CI}:-2.46$, 
$-0.15)$, and these differential relationships achieved statistical significance $(p=0.04$; Figure 1). Although similar patterns were found for each individual indicator of CR (Figure 1), the interaction terms between mood disorder and levels of education, occupation and social/cognitive activity did not achieve statistical significance (Table $3)$.

**Table 3 about here**

**Figure 1 about here**

The figures also show the extensive variance seen in cognitive performance in those with a mood disorder in comparison to those without a mood disorder or with a subthreshold mood disorder, regardless of cognitive reserve level.

\section{Discussion}

This study investigated whether cognitive reserve moderated the association between mood and cognitive function using a population-based study of older people in England. The presence of a subthreshold or clinical level mood disorder was associated with poorer cognitive performance, while higher levels of cognitive reserve were associated with better cognitive performance. Cognitive reserve did moderate the negative association between mood disorders and cognitive function. The difference in cognitive performance between those with and without a clinical level mood disorder was significantly smaller for those with medium or higher levels of cognitive reserve than for those with lower cognitive reserve. 
These results support our previous findings indicating that mild depressive symptoms and anxiety are negatively associated with cognitive function in those with lower cognitive reserve but not in those with higher cognitive reserve (Opdebeeck et al., 2015b). The current study expands upon these previous findings and suggests that similar moderating effects of cognitive reserve on the association between mood disorders and cognition are found as when self-reported symptoms that are mild and do not reach clinical levels are considered. In contrast, the observed effect was the opposite of that reported by O'Shea and colleagues (2015) and Geerlings and colleagues (2000) who reported that depression was associated with poorer cognitive performance and greater decline in those with higher education but not in those with lower education. The results also contrasted with several studies that have reported no significant interaction effect between proxy measures of cognitive reserve and mood on cognition (Bhalla et al., 2005; Wilson et al., 2004).

One possible explanation could be the differences between the study cohorts. CFAS II, a contemporary study of older people in the UK, has shown through comparison with earlier findings that there have been improvements in cognitive health over the past 20 years (Jagger et al., 2015; Matthews et al., 2013). The baseline level of cognitive reserve might be higher in CFAS II compared to other cohorts, for instance due to increased levels of education, which may result in a stronger moderation effect on the association of mood disorders with poorer cognitive performance. Another explanation for these differences is that the current study used a combination of life experiences to indicate levels of cognitive reserve while the contrasting studies consider only individual proxy measures of cognitive reserve, most commonly years of education. However, when we replicated the analysis with individual components, rather than lifetime cognitive reserve, the interactions were 
similar to those found with lifetime cognitive reserve but the individual component interactions were smaller and non-significant. These smaller and non-significant interactions demonstrate that it is probable that lifetime cognitive reserve has a stronger moderation effect than the individual components.

The design and contemporary nature of the CFAS II cohort allowed us to investigate whether cognitive reserve, considered in terms of multiple indicators, moderates the association between mood and cognition in several beneficial ways. It enabled the consideration of the differences between those with no mood disorder, a subthreshold disorder, and those with a clinical level mood disorder rather than low levels of depressive symptoms, as seen in several previous studies (Avila et al., 2009; Opdebeeck et al., 2015b; O’Shea et al., 2015). In addition, levels of a comprehensive, lifetime indicator of cognitive reserve were represented in tertiles rather than using dichotomies of individual or combined proxy measures of cognitive reserve as several previous studies have done (e.g. Avila et al., 2009; Bhalla et al., 2005; Opdebeeck et al., 2015b). This allowed an investigation of the finer detail of the effects of different levels of cognitive reserve. Nevertheless, there are several limitations to this study. As this was a cross-sectional study, it is not possible to determine the causal directions of the observed associations. Future research could consider examining whether a comprehensive proxy measure of cognitive reserve, including education, occupation, and current activities, moderates the longitudinal association between mood and incidence of cognitive impairment and dementia. A more comprehensive neuropsychological assessment than was employed here would allow for assessment of the effects within different domains of cognitive function and may give a better insight into the mechanisms of these associations, especially if combined with a longitudinal design. Additionally, there was greater variation in cognitive 
performance in those with a clinical mood disorder compared to those with no mood disorder, irrespective of level of cognitive reserve. This may indicate the operation of other influences not accounted for here, which could be investigated in future research. Furthermore, depression is generally a relapsing and remitting condition with different trajectories of depression showing different relationships with the risk of developing dementia (Mirza et al., 2016), indicating that people's past history of depression may be as, if not more, important than their current levels of depression. There may also be shared risk factors for, or causes of, both depression and cognitive decline or dementia other than cognitive reserve which could help explain the association between mood disorders and cognitive function; for example childhood nutrition has been associated with both mood and cognitive status in later life (Case \& Paxson, 2008; Heys et al., 2008; Whalley et al., 2006).

Stern (2002) theorised that healthy people with higher cognitive reserve are better able to cope with increasing task difficulty, while for those with brain damage or disease, cognitive reserve allows compensation through the recruitment of alternate neural networks or cognitive paradigms. It is possible that a mood disorder increases the challenge of cognitive tasks, for example due to reduced attentional control (Eysenck et al., 2007), and that those with higher cognitive reserve are better able to compensate for this increase in task demands than those with lower cognitive reserve. Several studies report increased activation in frontostriatal regions during executive function tasks in people with depression compared to those without depression when both groups have similar performance levels (e.g. Matsuo et al., 2007; see Pizzaglli, 2011 for a review), but reduced activation in people with depression when this group's task performance was poorer than that of people without depression (e.g. Harvey et al., 2005; Pizzagilli, 2011). As far as we are aware, no study has 
investigated differences in activation levels in people with and without depression by cognitive reserve level, but it is possible that cognitive reserve helps to compensate for the potential abnormality of frontostriatal circuit function in people with depression. Future research could investigate this possibility by examining the differing levels of activation during cognitive tasks in those with higher and lower levels of cognitive reserve and with and without a mood disorder.

Cognitive reserve has previously been described as a fluid construct and it has been suggested that it is possible to continue to build on existing reserve throughout the lifespan (Richards \& Deary, 2005; Richards \& Sacker, 2003; Whalley et al., 2006). Interventions in mid- and later life aimed at increasing cognitive reserve, such as incentives to engage in life-long learning programmes or cognitively-complex activities, could moderate the negative effect of mood disorders on cognition and support the maintenance of cognitive health in later life.

\section{Conclusion}

The findings of this study suggest that cognitive reserve is not only associated with better cognitive function in later life but also moderates the negative association between mood disorders and cognitive function. There is growing emphasis being placed on strategies to reduce the risk of cognitive decline and dementia and mood disorders have been recognised to be important risk factors for dementia. Enhancing cognitive reserve over the life course, through strategies such as increasing engagement in social and cognitive activities, may mitigate the negative impact of mood disorders on cognitive health in later life. 


\section{Contributors:}

The CFAS management committee all contributed to all aspects of the study including fund raising, design, supervision, acquiring the data, supporting and conducting the fieldwork and drafting; $\mathrm{CO}$ wrote the first draft and all authors edited the report, FEM $\& \mathrm{CB}$ conceived and designed the study, acquired the funds, acquired the data, supported and conducted the fieldwork; FEM consulted on the analysis; YTW conducted the analysis; RW \& LC assisted in the conceptualisation of the paper; CO and YTW are guarantors of the analysis.

\section{CFAS collaboration:}

CFAS core team and fieldwork support: E Green, L Gao, R Barnes, J Warwick, A Mattison. CFAS management committee membership: A Arthur, C Baldwin, L E Barnes, C Brayne, L Clare, A Comas-Herera, T Dening, G Forster, S Harrison, PG Ince, C Jagger, A S McDonald, F E Matthews, C F M McCracken, I G McKeith, C Moody, B Parry, L Robinson, B Stephan, S Wharton, R Wittenberg, B Woods. CFAS Biological resource advisory committee $-R$ Weller (chair).

\section{Conflicts of interest}

We declare that we have no conflicts of interest.

\section{Acknowledgements}

CFAS II has been supported by the UK Medical Research Council (research grant: G06010220) and received additional support from the National Institute for Health Research (NIHR), comprehensive clinical research networks in West Anglia, Nottingham City and Nottinghamshire County NHS Primary Care trusts and the dementias and neurodegenerative disease research Network (DeNDRoN) in Newcastle. This research was done within the UK National Institute of Health Research collaboration for leadership in applied health research and care for Cambridgeshire and Peterborough (CLAHRC EoE), and the Biomedical Research Centre infrastructures at Cambridge and Newcastle upon Tyne. FEM is supported by the MRC (research grant: U105292687).

We thank the participants, their families, the general practitioners and their staff, the primary care trusts and CCGs for their cooperation and support. We thank the CFAS 
II fieldwork interviewers at Cambridge, Nottingham and Newcastle for their valuable contribution.

\section{Role of funding source}

The funders are represented on the CFAS management committee and the biological resource advisory committee but they had no role in the study design, data analysis, data interpretation, or writing of the report. The first author had full access to all the data in the study and the corresponding author had the final responsibility for the decision to submit for publication.

\section{Ethical Standards}

The authors assert that all procedures contributing to this work comply with the ethical standards of the relevant national and institutional committees on human experimentation and with the Helsinki Declaration of 1975, as revised in 2008. 


\section{References}

Avila R, Moscoso MAA, Ribeiz S, Arrais J, Jaluul O, Bottino C (2009). Influence of education and depressive symptoms on cognitive function in the elderly. International Psychogeriatrics, 21, 560-567. doi: 10.1017/S1041610209008928

\section{Ballmaier M, Toga AW, Blanton RE, Sowell ER, Lavretsky H, Peterson J, Pham D,} Kumar A (2004). Anterior cingulate, gyrus rectus, and orbitofrontal abnormalities in elderly depressed patients: an MRI-based parcellation of the prefrontal cortex. American Journal of Psychiatry, 161, 99-108. doi: 10.1176/appi.ajp.161.1.99

Bhalla RK, Butters MA, Zmuda MD, Seligman K, Mulsant, BH, Pollock BG, Reynolds CF (2005). Does education moderate neuropsychological impairment in late-life depression? International Journal of Geriatric Psychiatry, 20, 413-417. doi: $10.1002 /$ gps. 1296

Byers AL, Yaffe K (2011). Depression and risk of developing dementia. Nature Reviews Neurology, 7, 323-331. doi: 10.1038/nrneurol.2011.60

Case A, Paxson C (2008). Height, health, and cognitive function at older ages. The American Economic Review, 98, 463. doi: 10.1257/aer.98.2.463

\section{Comas-Herrera A, Northey S, Wittenberg R, Knapp M, Bhattacharyya S, Burns A} (2011). Future costs of dementia-related long-term care: exploring future scenarios. International Psychogeriatrics, 23, 20-30. doi: 10.1017/S1041610210000025

Copeland JRM, Dewey ME, Griffiths-Jones HM (1986). A computerized psychiatric diagnostic system and case nomenclature for elderly subjects: GMS and AGECAT. Psychological Medicine, 16, 89-99. doi: 10.1017/S0033291700057779

Copeland JRM, Prince M, Wilson KCM, Dewey ME, Payne J, Gurland B (2002). The geriatric mental state examination in the 21 st century. International Journal of the Geriatric Psychiatry, 17, 729-732. doi: 10.1002/gps.667 


\section{Copeland JRM, Beekman ATF, Braam AW, Dewey ME, Delespaul P, Fuhrer R,} Hooijer C, Lawlor, BA, Kivela SL, Lobo A, Magnusson H (2004). Depression among older people in Europe: the EURODEP studies. World Psychiatry, 3, 45-49.

Debette S, Markus HS (2010). The clinical importance of white matter hyperintensities on brain magnetic resonance imaging: systematic review and meta-analysis. British Medical Journal, 341, 1-9. doi: 10.1136/bmj.c3666

Deckers K, Boxtel MP, Schiepers OJ, Vugt M, Muñoz Sánchez JL, Anstey KJ, Brayne C, Dartigues J-F, Engedal K, Kivipelto M, Ritchie K, Starr, JM, Yaffe K, Irving K, Verhey FRJ, Köhler S (2015). Target risk factors for dementia prevention: a systematic review and Delphi consensus study on the evidence from observational studies. International Journal of Geriatric Psychiatry, 30, 234-246. doi: $10.1002 /$ gps.4245

Di Carlo A, Baldereschi M, Amaducci L, Maggi S, Grigoletto F, Scarlato G, Inzitari D, for the Italian Longitudinal Study on Aging Working Group. (2000). Cognitive impairment without dementia in older people: prevalence, vascular risk factors, impact on disability. The Italian longitudinal study on aging. Journal of the American Geriatrics Society, 48, 775-782. doi: 10.1111/j.1532-5415.2000.tb04752.x

Diniz BS, Butters MA, Albert SM, Dew MA, Reynolds CF (2013). Late-life depression and risk of vascular dementia and Alzheimer's disease: systematic review and metaanalysis of community-based cohort studies. The British Journal of Psychiatry, 202, 329-335. doi: 10.1192/bjp.bp.112.118307

Elbejjani M, Fuhrer R, Abrahamowicz M, Mazoyer B, Crivello F, Tzourio C, Dufouil C (2015). Depression, depressive symptoms, and rate of hippocampal atrophy in a longitudinal cohort of older men and women. Psychological Medicine, 15, 1931-1944. doi: $10.1017 / \mathrm{S} 0033291714003055$ 
Enzinger C, Fazekas F, Matthews PM, Ropele S, Schmidt H, Smith S, Schmidt R (2005). Risk factors for progression of brain atrophy in aging: six-year follow-up of normal subjects. Neurology, 64, 1704-1711. doi: 10.1212/01.WNL.0000161871.83614.BB

Eysenck MW, Derakshan N, Santos R Calvo MG (2007). Anxiety and cognitive performance: attentional control theory. Emotion, 7, 336-353. doi: 10.1037/15283542.7.2.336

Fratiglioni L, Wang HX (2007). Brain reserve hypothesis in dementia. Journal of Alzheimer's Disease, 12, 11-22.

Geerlings MI, Schoevers RA, Beekman AT, Jonker C, Deeg DJ, Van Tilburg W, Adér HJ, Schmand B (2000). Depression and risk of cognitive decline and Alzheimer's disease. Results of two prospective community-based studies in the Netherlands. The British Journal of Psychiatry, 176, 568-575. doi: 10.1192/bjp.176.6.568

Gao L, Green E, Barnes LE, Brayne C, Matthews FE, Robinson L, Arthur A; Medical Research Council Cognitive Function and Ageing Collaboration (2015). Changing non-participation in epidemiological studies of older people: evidence from the Cognitive Function and Ageing Study I and II. Age and Ageing, 44, 867-73. doi: 10.1093/ageing/afv101

Harrison SL, Sajjad A, Bramer WM, Ikram MA, Tiemeier H, Stephan BC (2015). Exploring strategies to operationalize cognitive reserve: a systematic review of reviews. Journal of Clinical and Experimental Neuropsychology, 37, 253-264. doi: $10.1080 / 13803395.2014 .1002759$

Harvey PO, Fossati P, Pochon JB, Levy R, LeBastard G, Lehéricy S, Allilaire JF, Dubois B (2005). Cognitive control and brain resources in major depression: an fMRI study using the n-back task. Neuroimage, 26, 860-869. doi: 10.1016/j.neuroimage.2005.02.048 
Heys M, Jiang C, Schooling CM, Zhang W, Cheng KK, Lam TH, Leung GM (2010). Is childhood meat eating associated with better later adulthood cognition in a developing population? European Journal of Epidemiology, 25, 507-516. doi: 10.1007/s10654010-9466-0

Jagger C, Matthews R, Lindesay J, Robinson T, Croft P, Brayne C (2009). The effect of dementia trends and treatments on longevity and disability: a simulation model based on the MRC Cognitive Function and Ageing Study (MRC CFAS). Age and Ageing, 38, 319-325. doi; 10.1093/ageing/afp016

Jagger C, Matthews FE, Wohland P, Fouweather T, Stephan BC, Robinson, L, Arthur A, Brayne C, Medical Research Council Cognitive Function and Ageing Collaboration (2015). A comparison of health expectancies over two decades in England: results of the Cognitive Function and Ageing Study I and II. The Lancet, 387, 779-786. doi: 10.1016/S0140-6736(15)00947-2

Korczyn AD, Halperin I (2009). Depression and dementia. Journal of the Neurological Sciences, 283, 139-142. doi: 10.1016/j.jns.2009.02.346

\section{Langa KM, Larson EB, Karlawish JH, Cutler DM., Kabeto MU, Kim SY, Rosen AB} (2008). Trends in the prevalence and mortality of cognitive impairment in the United States: is there evidence of a compression of cognitive morbidity? Alzheimer's \& Dementia, 4, 134-144. doi: 10.1016/j.jalz.2008.01.001

Leonard BE (2007). Inflammation, depression and dementia: are they connected? Neurochemical Research, 32, 1749-1756. doi: 10.1007/s11064-007-9385-y

Lorant V, Deliège D, Eaton W, Robert A, Philippot P, Ansseau M (2003). Socioeconomic inequalities in depression: a meta-analysis. American Journal of Epidemiology, 157, 98-112. doi: 10.1093/aje/kwf182 


\title{
Matsuo K, Glahn DC, Peluso MAM, Hatch JP, Monkul ES, Najt P, Sanches M,
} Zamarripa F, Li J, Lancaster JL, Fox PT (2007). Prefrontal hyperactivation during working memory task in untreated individuals with major depressive disorder. Molecular Psychiatry, 12, 158-166. doi: 10.1038/sj.mp.4001894

\author{
Matthews FE, Arthur A, Barnes LE, Bond J, Jagger C, Robinson L, Brayne C, Medical \\ Research Council Cognitive Function and Ageing Collaboration (2013). A two- \\ decade comparison of prevalence of dementia in individuals aged 65 years and older \\ from three geographical areas of England: results of the Cognitive Function and \\ Ageing Study I and II. The Lancet, 382, 1405-1412. doi: 10.1016/S0140- \\ 6736(13)61570-6
}

Meng X, D'Arcy C (2012). Education and dementia in the context of the cognitive reserve hypothesis: a systematic review with meta-analyses and qualitative analyses. PLoS One, 7, e38268. doi: 10.1371/journal.pone.0038268

Mirza SS, Wolters FJ, Swanson SA, Koudstaal PJ, Hofman A, Tiemeier H, Ikram MA (2016). 10-year trajectories of depressive symptoms and risk of dementia: a population-based study. The Lancet Psychiatry, 3, 628-635. doi: 10.1016/S22150366(16)00097-3

McDougall FA, Kvaal K, Matthews FE, Paykel E, Jones PB, Dewey ME, Brayne C (2007). Prevalence of depression in older people in England and Wales: the MRC CFA study. Psychological Medicine, 37, 1787-1795. doi: $10.1017 / \mathrm{S} 0033291707000372$

Nebes RD, Vora IJ, Meltzer CC, Fukui MB, Williams RL, Kamboh MI, Saxton J, Houck PR, DeKosky ST, Reynolds CF (2001). Relationship of deep white matter hyperintensities and apolipoprotein E genotype to depressive symptoms in older 
adults without clinical depression. American Journal of Psychiatry, 158, 878-884. doi: 10.1176/appi.ajp.158.6.878

Norton S, Matthews FE, Barnes LD, Yaffe K, Brayne C (2014). Potential for primary prevention of Alzheimer's disease: an analysis of population-based data. Lancet Neurology, 13, 788-794. 10.1016/S1474-4422(14)70136-X

Opdebeeck C, Martyr A, Clare L (2016a). Cognitive reserve and cognitive function in healthy older people: a meta-analysis. Aging, Neuropsychology, and Cognition, 23, 40-60. doi: 10.1080/13825585.2015.1041450

Opdebeeck C, Quinn C, Nelis SM, Clare L (2016b). Is cognitive lifestyle associated with depressive thoughts and self-reported depressive symptoms in later life? European Journal of Ageing, 13, 63-73. doi: 10.1007/s10433-015-0359-7

Opdebeeck C, Quinn C, Nelis SM, Clare L (2015a). Does cognitive reserve moderate the association between mood and cognition? A systematic review. Reviews in Clinical Gerontology, 25, 181-193. doi: 10.1017/S0959259815000155

Opdebeeck C, Nelis SM, Quinn C, Clare L (2015b). How does cognitive reserve impact on the relationships between mood, rumination, and cognitive function in later life? Aging \& Mental Health, 19, 705-712. doi: 10.1080/13607863.2014.962005

O’Brien JT, Lloyd A, McKeith I, Gholkar A, Ferrier N (2004). A longitudinal study of hippocampal volume, cortisol levels, and cognition in older depressed subjects. American Journal of Psychiatry, 161, 2081-2090. doi: 10.1176/appi.ajp.161.11.2081 O'Shea DM, Fieo RA, Hamilton JL, Zahodne LB, Manly JJ, Stern Y (2015). Examining the association between late-life depressive symptoms, cognitive function, and brain volumes in the context of cognitive reserve. International Journal of Geriatric Psychiatry, 30, 614-622. doi: 10.1002/gps.4192 
Pálsson S, Aevarsson O, Skoog I (1999). Depression, cerebral atrophy, cognitive performance and incidence of dementia. Population study of 85-year-olds. The British Journal of Psychiatry, 174, 249-253. doi: 10.1192/bjp.174.3.249

Pálsson S, Larsson L, Tengelin E, Waern M, Samuelsson S, Hallstro T, Skoog I (2001). The prevalence of depression in relation to cerebral atrophy and cognitive performance in 70- and 74-year-old women in Gothenburg. The Women's Health Study. Psychological Medicine, 31, 39-49. Retrieved from http://journals.cambridge.org/action/displayAbstract?fromPage=online\&aid $=64011 \& \mathrm{f}$ ileId $=$ S0033291799003050

Paulson D, Bowen ME, Lichtenberg PA (2014). Does brain reserve protect older women from vascular depression? The Journals of Gerontology. Series B, Psychological Sciences and Social Sciences, 69, 157-167. doi: 10.1093/geronb/gbt007

Pérès K, Verret C, Alioum A, Barberger-Gateau P (2005). The disablement process: factors associated with progression of disability and recovery in French elderly people. Disability \& Rehabilitation, 27, 263-276. doi: 10.1080/09638280400006515

Pizzagalli DA (2011). Frontocingulate dysfunction in depression: toward biomarkers of treatment response. Neuropsychopharmacology, 36, 183-206. doi:

$10.1038 /$ npp. 2010.166

\section{Reppermund S, Brodaty H, Crawford JD, Kochan NA, Slavin MJ, Trollor JN, Draper}

B, Sachdev PS (2011). The relationship of current depressive symptoms and past depression with cognitive impairment and instrumental activities of daily living in an elderly population: the Sydney memory and ageing study. Journal of Psychiatric Research, 45, 1600-1607. doi:10.1016/j.jpsychires.2011.08.001 
Richards M, Deary IJ (2005). A life course approach to cognitive reserve: a model for cognitive aging and development? Annals of Neurology, 58, 617-622. doi: 10.1002/ana.20637

Richards M, Sacker A (2003). Lifetime antecedents of cognitive reserve. Journal of Clinical and Experimental Neuropsychology, 25, 614-624. doi: 10.1076/jcen.25.5.614.14581

\section{Roth MTYME, Tym E, Mountjoy CQ, Huppert FA, Hendrie H, Verma S, Goddard R} (1986). CAMDEX. A standardised instrument for the diagnosis of mental disorder in the elderly with special reference to the early detection of dementia. The British Journal of Psychiatry, 149, 698-709. doi: 10.1192/bjp.149.6.698

\section{Santos NC, Costa PS, Cunha P, Portugal-Nunes C, Amorim L, Cotter J, Cerqueira J, Palha JA, Sousa N (2014). Clinical, physical and lifestyle variables and relationship with cognition and mood in aging: a cross-sectional analysis of distinct educational groups. Frontiers in Aging Neuroscience, 6, doi: 10.3389/fnagi.2014.00021}

St John PD, Tyas SL, Montgomery PR (2015). Cognition, even in the normal range, predicts disability: cross-sectional and prospective analyses of a population-based sample. International Journal of Geriatric Psychiatry, 30, 1008-1016. doi: $10.1002 / \mathrm{gps} .4254$

Steffens DC, McQuoid DR, Potter GG (2014). Amnestic mild cognitive impairment and incident dementia and Alzheimer's disease in geriatric depression. International Psychogeriatrics, 26, 2029-2036. doi: 10.1017/S1041610214001446

Stern Y (2002). What is cognitive reserve? Theory and research application of the reserve concept. Journal of the International Neuropsychological Society, 8, 448-460. doi: $10.1017 / \mathrm{S} 1355617702813248$

Stern Y (2009). Cognitive reserve. Neuropsychologia, 47, 2028. doi: 10.1016/j.neuropsychologia.2009.03.004 
Stern Y (2011). Elaborating a hypothetical concept: comments on the special series on cognitive reserve. Journal of the International Neuropsychological Society, 17, 639642. doi: 10.1017/S1355617711000579

Tinetti ME, McAvay GJ, Chang SS, Newman AB, Fitzpatrick AL, Fried TR Peduzzi PN (2011). Contribution of Multiple Chronic Conditions to Universal Health Outcomes. Journal of the American Geriatrics Society, 59, 1686-1691. doi: 10.1111/j.15325415.2011.03573.x

Valenzuela M, Brayne C, Sachdev P, Wilcock G (2011). Cognitive lifestyle and long-term risk of dementia and survival after diagnosis in a multicentre population-based cohort. American Journal of Epidemiology, 173, 1004-1012. doi: 10.1093/aje/kwq476

Valenzuela MJ Sachdev P (2006a). Brain reserve and dementia: a systematic review. Psychological Medicine, 36, 441-454. doi: 10.1017/S003329170500626

Valenzuela MJ, Sachdev P (2006b). Brain reserve and cognitive decline: a non-parametric systematic review. Psychological Medicine, 36, 1065-1074. doi: $10.1017 / \mathrm{S} 0033291706007744$

Whalley LJ, Dick FD, McNeill G (2006). A life-course approach to the aetiology of lateonset dementias. The Lancet Neurology, 5, 87-96. doi: 10.1016/S14744422(05)70286-6

Williams JG, Huppert FA, Matthews FE, Nickson J; MRC Cognitive Function and Ageing Study (MRC CFAS). Performance and normative values of a concise neuropsychological test (CAMCOG) in an elderly population sample. International Journal of Geriatric Psychiatry, 18, 631-44. doi: 10.1002/gps.886

Wilson RS, De Leon CM, Bennett DA, Bienias JL, Evans DA (2004). Depressive symptoms and cognitive decline in a community population of older persons. Journal 
of Neurology, Neurosurgery \& Psychiatry, 75, 126-129. Retrieved from http://jnnp.bmj.com/content/75/1/126.short

Yates JA, Clare L, Woods RT (2013). Mild cognitive impairment and mood: a systematic review. Reviews in Clinical Gerontology, 23, 317-356. doi:

$10.1017 / \mathrm{S} 0959259813000129$ 

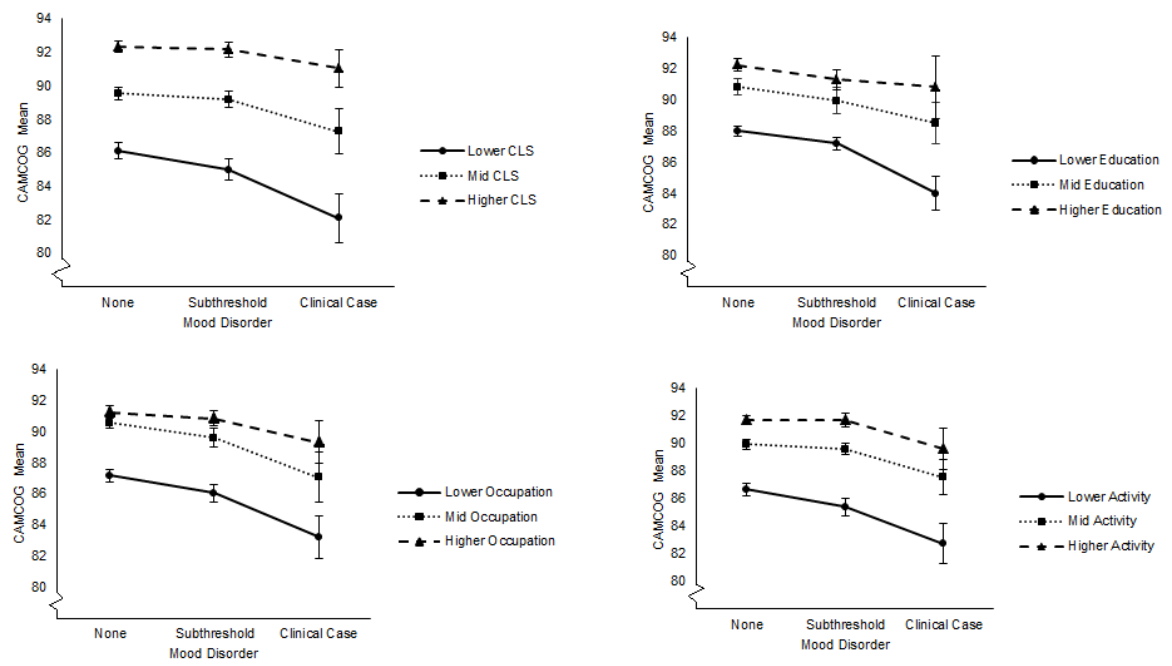

Figure 1: Mean cognitive performance by cognitive reserve group (CLS), educational level, occupation group, and social and cognitive activity level, and level of mood disorder. Error bars represent 95\% Confidence Intervals 
Table 1: Sex, age, education and level of depressive disorder for those included in the analysis and those with missing data

\begin{tabular}{|c|c|c|c|c|c|c|}
\hline \multirow[b]{2}{*}{ Age (mean (std.)) } & & \multicolumn{2}{|c|}{$\begin{array}{r}\text { Included in analysis } \\
\qquad(\mathrm{N}=6565)\end{array}$} & \multicolumn{2}{|c|}{$\begin{array}{r}\text { Any missing data on } \\
\text { cognitive function or } \\
\text { cognitive reserve } \\
(\mathrm{N}=629)\end{array}$} & $p$-value ${ }^{1}$ \\
\hline & & 74.8 & $(6.8)$ & 78.3 & (7.9) & $<0.01$ \\
\hline \multirow[t]{2}{*}{ Sex (N (\%)) } & Men & 3115 & (47.4) & 202 & $(32.1)$ & $<0.01$ \\
\hline & Women & 3450 & (52.6) & 427 & $(67.9)$ & \\
\hline \multirow[t]{3}{*}{ Depression (N (\%)) } & None & 5130 & (78.1) & 458 & (72.8) & $<0.01$ \\
\hline & Subthreshold & 1022 & (15.6) & 113 & $(18.0)$ & \\
\hline & Clinical case & 413 & $(6.3)$ & 58 & $(9.2)$ & \\
\hline \multirow[t]{3}{*}{ Anxiety (N (\%)) } & None & 4452 & $(67.8)$ & 425 & (67.6) & 0.03 \\
\hline & Subthreshold & 1971 & $(30.0)$ & 180 & (28.6) & \\
\hline & Clinical case & 142 & $(2.2)$ & 24 & $(3.8)$ & \\
\hline \multirow[t]{3}{*}{ Mood disorder (N (\%)) } & None & 3935 & $(59.9)$ & 366 & $(58.2)$ & 0.03 \\
\hline & Subthreshold & 2137 & (32.6) & 197 & $(31.3)$ & \\
\hline & Clinical case & 493 & $(7.5)$ & 66 & $(10.5)$ & \\
\hline $\begin{array}{l}\text { CAMCOG (mean } \\
\text { (std.)) }\end{array}$ & & 89.4 & (7.7) & & & \\
\hline $\begin{array}{l}\text { Cognitive lifestyle } \\
\text { score }\end{array}$ & Total & 86.9 & $(16.2)$ & & & \\
\hline \multirow[t]{3}{*}{ (mean (std.)) } & Education & 10.9 & $(2.5)$ & & & \\
\hline & Occupation & 7.6 & $(3.2)$ & & & \\
\hline & Activity & 31.7 & $(6.2)$ & & & \\
\hline
\end{tabular}

${ }^{1 .} \mathrm{p}$-value for t-test (age) or Chi-square test (other variables) 
Table 2: Weighted linear regression models for cognitive performance regressed on cognitive reserve (CLS) and level of mood disorder

\begin{tabular}{|c|c|c|c|c|c|}
\hline & & Model 1 & Model 2 & Model 3 & Model 4 \\
\hline & & Est. $(95 \% \mathrm{CI})$ & Est. $(95 \% \mathrm{CI})$ & Est. $(95 \%$ & Est. $(95 \% \mathrm{CI})$ \\
\hline & & & & (I) & \\
\hline \multirow[t]{3}{*}{ Age } & & -0.40 & -0.40 & -0.33 & -0.33 \\
\hline & & $(-0.43,-0.37)$ & $(-0.43,-0.37)$ & $\begin{array}{r}(-0.36,- \\
0.30)\end{array}$ & $(-0.36,-0.30)$ \\
\hline & p. & $<0.01$ & $<0.01$ & $<0.01$ & $<0.01$ \\
\hline \multirow[t]{4}{*}{ Sex } & Men (reference) & - & - & - & - \\
\hline & Women & -1.41 & -0.63 & -1.29 & -1.10 \\
\hline & & $(-1.83,-1.00)$ & $(-1.01,-0.25)$ & $\begin{array}{r}(-1.66,- \\
0.93)\end{array}$ & $(-1.47,-0.73)$ \\
\hline & p. & $<0.01$ & $<0.01$ & $<0.01$ & $<0.01$ \\
\hline \multirow{6}{*}{$\begin{array}{l}\text { Mood } \\
\text { disorder }\end{array}$} & None (reference) & - & - & & - \\
\hline & Subthreshold & -1.10 & -1.02 & & -0.57 \\
\hline & & $(-1.55,-0.65)$ & $(-1.44,-0.60)$ & & $(-0.96,-0.18)$ \\
\hline & Clinical case & -3.72 & -3.67 & & -2.77 \\
\hline & & $(-4.70,-2.74)$ & $(-4.59,-2.75)$ & & $(-3.61,-1.91)$ \\
\hline & p. & $<0.01$ & $<0.01$ & & $<0.01$ \\
\hline \multirow[t]{6}{*}{ CLS } & Low (reference) & - & & - & - \\
\hline & Middle & 4.42 & & 4.00 & 3.86 \\
\hline & & $(3.92,4.93)$ & & $(3.52,4.48)$ & $(3.38,4.34)$ \\
\hline & High & 7.77 & & 6.94 & 6.77 \\
\hline & & $(7.29,8.25)$ & & $(6.48,7.39)$ & $(6.32,7.22)$ \\
\hline & p. & $<0.01$ & & $<0.01$ & $<0.01$ \\
\hline
\end{tabular}

p.: p-value of test for heterogeneity

Model 1: Univariate model

Model 2: Multivariable model including age, sex and mood disorder

Model 3: Multivariable model including age, sex and cognitive reserve (CLS)

Model 4: Multivariable model including age, sex, mood disorder and cognitive reserve

All models were adjusted for missing data 
Table 3: Changes in cognitive performance by the interaction terms of cognitive reserve level and mood disorder

\begin{tabular}{|c|c|c|c|c|c|c|c|c|c|}
\hline \multirow{4}{*}{ Cognitive reserve } & \multirow{4}{*}{ Mood disorder } & \multicolumn{2}{|l|}{ CLS } & \multicolumn{2}{|l|}{ Education } & Occupation & \multicolumn{3}{|c|}{ Activity } \\
\hline & & Model 1 & Model 2 & Model 1 & Model 2 & Model 1 & Model 2 & Model 1 & Model 2 \\
\hline & & Est. $(95 \%$ & Est. $(95 \% \mathrm{CI})$ & Est. $(95 \% \mathrm{CI})$ & Est. $(95 \% \mathrm{CI})$ & Est. $(95 \% \mathrm{CI})$ & Est. $(95 \% \mathrm{CI})$ & Est. $(95 \% \mathrm{CI})$ & Est. $(95 \% \mathrm{CI})$ \\
\hline & & CI) & & & & & & & \\
\hline \multirow{3}{*}{ Low } & Subthreshold & -1.12 & -1.12 & -0.84 & -0.81 & -1.24 & -1.12 & -1.31 & -1.28 \\
\hline & & $(-1.96,-0.27)$ & $(-1.91,-0.31)$ & $(-1.42,-0.27)$ & $(-1.35,-0.26)$ & $(-1.99,-0.48)$ & $(-1.82,-0.43)$ & $(-2.16,-0.46)$ & $(-2.08,-0.49)$ \\
\hline & Clinical case & -3.89 & -4.01 & -3.96 & -4.01 & -4.00 & -3.94 & -4.02 & -3.94 \\
\hline \multirow[t]{6}{*}{ Middle } & None & 3.92 & 3.43 & 3.45 & 2.84 & 2.75 & 3.41 & 3.69 & 3.26 \\
\hline & & $(3.28,4.57)$ & $(2.82,4.05)$ & $(2.82,4.09)$ & $(2.25,3.43)$ & $(2.16,3.34)$ & $(2.83,3.99)$ & $(3.05,4.33)$ & $(2.68,3.85)$ \\
\hline & Subthreshold & 3.48 & 3.06 & 2.41 & 1.94 & 1.82 & 2.44 & 3.15 & 2.92 \\
\hline & & $(2.76,4.21)$ & $(2.37,3.76)$ & $(1.41,3.41)$ & $(1.03,2.84)$ & $(1.08,2.56)$ & $(1.71,3.16)$ & $(2.44,3.86)$ & $(2.26,3.58)$ \\
\hline & Clinical case & 1.53 & 1.16 & 1.02 & 0.50 & -0.65 & -0.09 & 1.06 & 0.89 \\
\hline & & $(0.00,3.06)$ & $(-0.27,2.59)$ & $(-0.56,2.61)$ & $(-0.88,1.87)$ & $(-2.41,1.12)$ & $(-1.73,1.55)$ & $(-0.38,2.51)$ & $(-0.45,2.22)$ \\
\hline \multirow{2}{*}{ High } & Clinical case & 5.57 & 4.92 & 3.45 & 2.81 & 1.81 & 2.16 & 3.13 & 2.95 \\
\hline & & $(4.28,6.86)$ & $(3.70,6.15)$ & $(1.43,5.47)$ & $(0.78,4.85)$ & $(0.18,3.44)$ & $(0.73,3.59)$ & $(1.53,4.73)$ & $(1.39,4.50)$ \\
\hline \multicolumn{2}{|c|}{$\mathrm{p}$-value for interaction terms } & 0.18 & 0.04 & 0.29 & 0.17 & 0.68 & 0.22 & 0.25 & 0.07 \\
\hline
\end{tabular}

Model 1: Univariate model adjusted for missing data

Model 2: Multivariable model adjusted for age, sex and missing data 